To Cite: Yıldırım E, Kumlutaş Y, Candan K, Ilgaz Ç, 2021. The Study on the Relationships Between the Age Structure and Body Size of the Bridled Skink, Heremites vittatus, (Oliver, 1804) from Different Altitudes in Turkey. Journal of the Institute of Science and Technology, 11(2): 906-915.

\title{
The Study on the Relationships Between the Age Structure and Body Size of the Bridled Skink, Heremites vittatus, (Oliver, 1804) from Different Altitudes in Turkey
}

\author{
Elif YILDIRIM $^{1 *}$, Yusuf KUMLUTAŞ ${ }^{1}$, Kamil CANDAN $^{1}$, Çetin ILGAZ ${ }^{1}$
}

\begin{abstract}
Age structure and body size of Heremites vittatus from three different altitudes (group I: 0-499 m, group II: 500-999 m, and group III: above $1000 \mathrm{~m}$ ) were investigated using skeletochronology. The mean snout-vent length (SVL) of females in all groups was larger than males. The average SVL was $74.8 \mathrm{~mm}$ in females and $66.8 \mathrm{~mm}$ in males. Age ranged from three to seven years in females and two to seven years in males. No significant differences were found in mean age between sexes (MannWhitney U-test, $\mathrm{p}=0.324$ ). Among three groups, there was no significant difference between the populations as regards both age and SVL. However, SVL only in groups I and II were statistically significant between sexes. Moreover, there was no significant correlation between age and SVL. The Von Bertalanffy's model indicated that females had a larger asymptotic body size than males and that there was a significant difference between the sexes in terms of growth rate.
\end{abstract}

Keywords: Skeletochronology, altitude, Heremites vittatus, Turkey

${ }^{1}$ Elif YILDIRIM (Orcid ID: 0000-0001-9614-5754), Yusuf KUMLUTAŞ (Orcid ID: 0000-0003-1154-6757), Kamil CANDAN (Orcid ID: 0000-0002-6934-3971), Çetin ILGAZ (Orcid ID: 0000-0001-7862-9106), Dokuz Eylül University, Faculty of Science, Biology Department, Turkey

*Corresponding Author: Elif YILDIRIM, e-mail: yildirim.elif@deu.edu.tr 


\section{INTRODUCTION}

The family Scincidae is one of the largest families that has a worldwide distribution (Whiting et al., 2006). Bridled Skink, Heremites vittatus (Oliver, 1804) is a medium-sized species that is one of 1642 described lizards. Heremites vittatus has been found in Algeria, Cyprus, Egypt, Israel, Jordan, Lebanon, Libya, Syrian Arab Republic, Tunisia and Turkey. In Turkey, this species is distributed throughout southern parts in different altitudes and found in open areas of sandy or stony soil with vegetation (Baran et al., 2012).

Oliver (1804) described this species as Scincus vittatus for the first time. The taxonomic status of $H$. vittatus has been treated so many times. Previously this species was located in the genus Mabuya that was assigned to the genus Euprepis and then re-assigned to Trachylepis (Mausfeld et al., 2000; Mausfeld et al., 2002; Bauer, 2003). Finally, Karin et al. (2016) placed this species in a different genus Heremites.

Data on the life-history are important to address the evolution, ecology and conservation biology of reptilian species (Grimm et al., 2014). To determine the patterns of variations in age structure is a part of the life-history of species. Skeletochronology is one of the most common methods to estimate the age structure of the reptilian species because of more accurate and timesaving than other age determination methods such as mark-recapture methods. Skeletochronology estimates the age of species by counting lines of arrested growth layers during hibernation periods (Tomaševiḉ et al., 2010; Altunış1k et al., 2013; Gül et al., 2014; Yakin and Tok, 2015). Many studies on lizards have been recently performed by using skeletochronology (Orlova and Smirina, 1983, Darevskia derjugini; Kim et al., 2010, Eremias argus; Kolarov et al., 2010, Dinarolacerta mosorensis; Arakelyan et al., 2013, Darevskia armeniaca, D. uzzelli, D. sapphirina, D. unisexualis; Gül et al., 2014, Darevskia rudis; Cabezas-Cartes, Boretto ve Ibargüengoytía, 2015, Phymaturus spectabilis; Gül et al., 2015a, Apathya cappadocica; Gül et al., 2015b, Darevskia bithynica; Üzüm et al., 2015, Eremias suphani; Bülbül et al., 2016a, Darevskia parvula; Bülbül et al., 2016b, Darevskia clarkorum; Altunış1k et al., 2016, Podarcis tauricus; Kurnaz et al., 2017, Darevskia valentini; Eroğlu et al., 2017, Podarcis siculus, Üzüm et al., 2018, Phoenicolacerta laevis; Eroğlu et al., 2018, Podarcis muralis; Altunışık and Eksilmez, 2018, Darevskia dryada; Mermer et al., 2020, Chalcides ocellatus).

Data on new locality, osteology, and phylogenetic of $H$. vittatus exist in the literature (Güçlü et al., 2014; Rastergar-Pouyani et al., 2013; Kumlutaş et al., 2015). However, there is limited data about life-history such as age structure, growth pattern, or longevity of $H$. vittatus (Kalayc1 et al., 2018). In the present study, age structure, body size, and growth pattern of $H$. vittatus were studied in different Turkish populations living along an altitudinal gradient from 9 to $2042 \mathrm{~m}$ in order to determine if the demographic life-history traits of $H$. vittatus differ concerning different altitudinal conditions.

\section{MATERIALS AND METHODS}

\section{Study Site and Sampling}

A total of 118 museum specimens were collected from twenty-four populations at three different altitudes (Group I: 0-499 m, group II: 500-999 m, and group III: above 1000 m) from April to November (Table 1). Moreover, the species spends at least six months in hibernation, from late October to late March. Each individual was caught by hand in the daytime. All museum specimens examined here were stored in the Fauna Flora Applied and Research Center, Dokuz Eylül University. Snout-vent lengths (SVLs) of the specimens were measured with a caliper to 
the nearest $0.1 \mathrm{~mm}$. Sex was determined by the examination of the secondary sexual characters (e.g. smaller head, narrower bodies, and smaller length of the cloacal aperture in males Rastegar-Pouyani and Fattahi, 2015). Sexual size dimorphism was quantified by the sexual dimorphism index as described by the formula calculated according to Lovich and Gibbons (1992): SDI = (mean SVL of the larger sex / mean SVL of the smaller sex $) \pm 1$. The value +1 is used if males are larger than females and -1 if the opposite is true. SDI was defined as positive if females were larger and negative if males were larger.

\section{Skeletochronological Analyses}

For each individual, the phalanx of the longest finger of the hind limb was cut and fixed in $70 \%$ ethanol and decalcified by $5 \%$ nitric acid for 2 hours. Then, a routine histological technique was used for subsequent steps. $16 \mu$ of diaphyseal cross-sections was prepared by using a rotary microtome and stained with Hematoxylin for 20 minutes (Fig. 1).

Statistical Analyses. The normality of the SVL and age distribution for each sex was tested with the Kolmogorov-Smirnov test $(\mathrm{P} \geq 0.05)$. After we tested variables normality, parametric tests were applied to test significant differences for normally distributed variables. Non-parametric tests were used when variables were not normally distributed. All statistical tests were performed by IBM SPSS 23.0 for Windows.

\section{Growth pattern}

The von Bertalanffy's model between body size and age was used for the growth pattern estimation of lizards (James, 1991; Wapstra et al., 2001; Roitberg and Smirina, 2006b; Guarino et al., 2010). The general formula of the von Bertalanffy equation used is $\left.\mathrm{L}_{t}=\mathrm{L}_{\infty}\left(1-\mathrm{e}^{-\mathrm{k}(\mathrm{t}-\mathrm{t}}\right)_{0}\right)$, where $\mathrm{L}_{\mathrm{t}}$ is the length at age $\mathrm{t}, \mathrm{L}_{\infty}$ is a parameter indicating the asymptotic maximum length, $\mathrm{e}$ is the base of the natural logarithm, $\mathrm{k}$ is a growth coefficient and $t_{0}$ is the age at hatching.

Table 1. Population and sample size $(\mathrm{N})$ of Heremites vittatus

\begin{tabular}{|c|c|c|c|c|c|c|c|c|}
\hline \multicolumn{3}{|c|}{ Group I } & \multicolumn{3}{|c|}{ Group II } & \multicolumn{3}{|c|}{ Group III } \\
\hline Population & Altitude (m) & $\mathbf{N}$ & Population & Altitude (m) & $\mathbf{N}$ & Population & Altitude (m) & $\mathrm{N}$ \\
\hline Hatay & $258 / 108 / 226 / 73 / 9$ & 12 & Adiyaman & 601 & 11 & Ankara & & 1 \\
\hline Şanlıurfa & $370 / 445$ & 6 & Hatay & $632 / 976$ & 4 & Mersin & 1228 & 2 \\
\hline Antalya & $139 / 28 / 96$ & 4 & Gaziantep & $958 / 732 / 854 / 519$ & 12 & Gümüşhane & $1951 / 2042 / 1668 / 1892$ & 6 \\
\hline Kilis & 460 & 1 & Siirt & $804 / 704$ & 2 & Sivas & $1436 / 1397 / 1559 / 1544 / 1436$ & 7 \\
\hline Şırnak & $414 / 466 / 456$ & 17 & Şanlıurfa & $644 / 723 / 600$ & 10 & Mersin & $1297 / 1313 / 1412 / 1196$ & 14 \\
\hline Mersin & $57 / 9$ & 4 & Mersin & $953 / 727$ & 3 & Kahramanmaraş & 1480 & 4 \\
\hline \multirow[t]{3}{*}{ Gaziantep } & 492 & 6 & Kilis & $802 / 602$ & 5 & Diyarbakır & 1117 & 8 \\
\hline & & 50 & Kahramanmaraş & 976 & 3 & Afyon & 1226 & 1 \\
\hline & & & & & 50 & Gaziantep & 1114 & 1 \\
\hline
\end{tabular}

\section{RESULTS AND DISCUSSION}

Age ranged from 3 to 7 years in females, and 2 to 7 years in males. The mean SVL of the specimens was $72.8,71.6$ and $68.5 \mathrm{~mm}$ from the lowest to highest elevation sites whereas the mean age was 4.32, 4.83 and 4.95, respectively. The average age and SVL of each sex of H. vittatus at different altitudes are given in Table 2 .

Table 2. Mean body size and age of Heremites vittatus from low to high altitudes within each sex

\begin{tabular}{|c|c|c|c|c|c|c|}
\hline & \multicolumn{2}{|c|}{ Group I (Low altitudes) } & \multicolumn{2}{|c|}{ Group II (Medium altitudes) } & \multicolumn{2}{|c|}{ Group III (High altitudes) } \\
\hline & SVL (mm) & Age (years) & SVL (mm) & Age (years) & SVL (mm) & Age (years) \\
\hline Female & 77.7 & 4.52 & 75 & 4.85 & 71.8 & 5 \\
\hline Male & 68.2 & 4.59 & 67.4 & 4.53 & 63.4 & 4.61 \\
\hline
\end{tabular}


In group I, the minimum age was found to be 2 years for males and 3 for females whereas the maximum age was 7 for both males and females (Fig. 2A). The mean age of the specimens in group I was not significantly different between the sexes (Mann-Whitney $\mathrm{U}$ test; $\mathrm{P}=0.814$ ). However, a significant difference was found between sexes in terms of SVL (Independent Samples t-test: $\mathrm{t}=4.017$, $\mathrm{P}=0.000$ ). There was no correlation between age and $\mathrm{SVL}$ for both sexes (Spearman correlation: $\mathrm{r}=$ $0.285, \mathrm{P}=079)$.

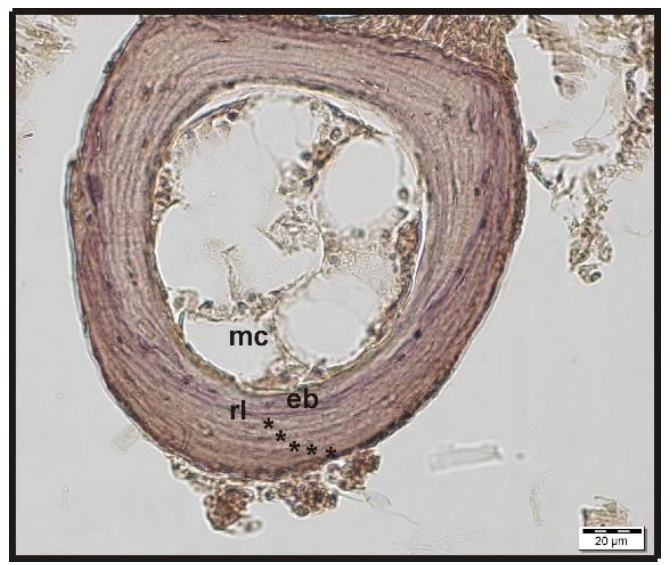

Figure 1. A cross-section at the diaphysis level of phalanx of Heremites vittatus (5 years). eb, endosteal bone; mc, marrow cavity; rl, resorption line

In group II, the minimum age was 3 in females and 4 in males and the maximum age was found to be 6 in males and 7 in females (Fig. 2B). The mean age of the specimens did not differ significantly between sexes (Man-Whitney $\mathrm{U}$ test: $\mathrm{P}=0.476$ ). Moreover, SVL was significantly different between sexes (Independent Sample t-test: $\mathrm{t}=2.898, \mathrm{P}=0.006$ ). There is no correlation between age and SVL for both sexes (Spearman correlation: $\mathrm{r}=0.160, \mathrm{P}=281$ ).

In group III, the minimum age was 3 in females and 4 in males while the maximum age was found to be 6 in males and 7 in females (Fig. 2C). The mean age of the specimens did not differ significantly between sexes (Man-Whitney $\mathrm{U}$ test: $\mathrm{P}=0.220$ ). However, SVL was significantly different between sexes (Independent Sample t-test: $\mathrm{F}=1.717, \mathrm{t}=2.895, \mathrm{P}=0.07$ ). There was no correlation between age and SVL for females and males (Spearman correlation: $\mathrm{r}=0.155, \mathrm{P}=398$ ).

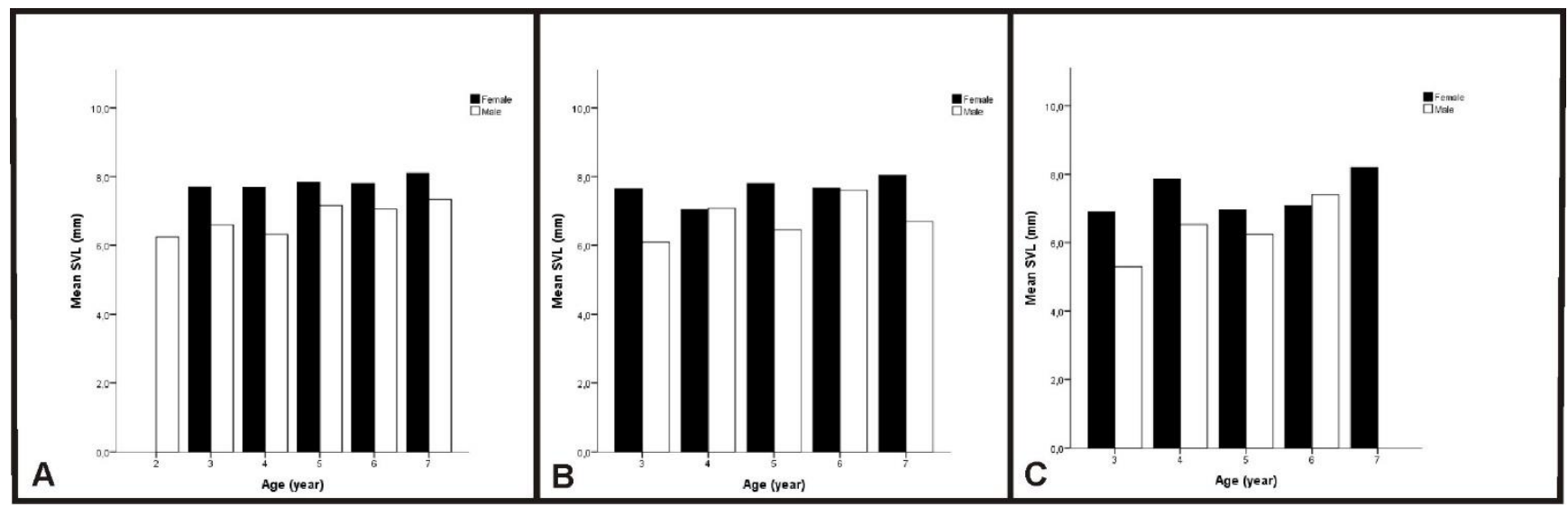

Figure 2. Relationships between SVL and age of Heremites vittatus from three groups. A. group I, B. group II and C. group III.

Females of $H$. vittatus were larger than males in terms of mean SVL. However, no significant difference was found between sexes in terms of the mean SVL (Student t-test: $t=0.500, P=0.667$ ). No significant difference was found both for SVL and age of individuals that inhabited three different 
elevations, respectively (ANOVA: $\mathrm{F}=1.050, \mathrm{P}=0.354$; Kruskal-Wallis test: Chi-Square=1.215; $\mathrm{P}=0.545$ ).

Females were on average older than males. Therefore, the mean age of males was not significantly higher than females (Independent samples t-test: $\mathrm{t}=1.215, \mathrm{P}=0.227$ ). In addition, females were significantly larger than males (Mann-Whitney test: $\mathrm{P}=.000$ ). The intersexual difference in SVL was male-biased (SDI $=-0.10$ ) when we considered for twenty-four populations in three groups. The intersexual difference in SVL was female-biased (SDI=0.13) in groups I and III, while this difference was male-biased (SDI=-0.10) in group II. Moreover, SVL of group I and III had a significant difference in itself, there is no significant relation between group I and III (Independent Sample t-test: $\mathrm{t}=1.251$, $\mathrm{P}=0.216$ ). According to Spearman correlation, age and SVL were not correlated in females and males inhabiting three altitudes $(r=.093, \mathrm{P}=0.493 ; \mathrm{r}=.216, \mathrm{P}=0.94)$. von Bertalanffy's model showed that the estimated asymptotic SVL was not higher than the maximum SVL recorded (SVLasym, males: $69 \mathrm{~mm}$; females: $76 \mathrm{~mm}$ ). The growth coefficient was higher in females than in males (k, males: 0.769; females: 0.959). The growth curve of males was significantly different from that of females $(t=3.827, P=0.001)$ (Fig. 3).

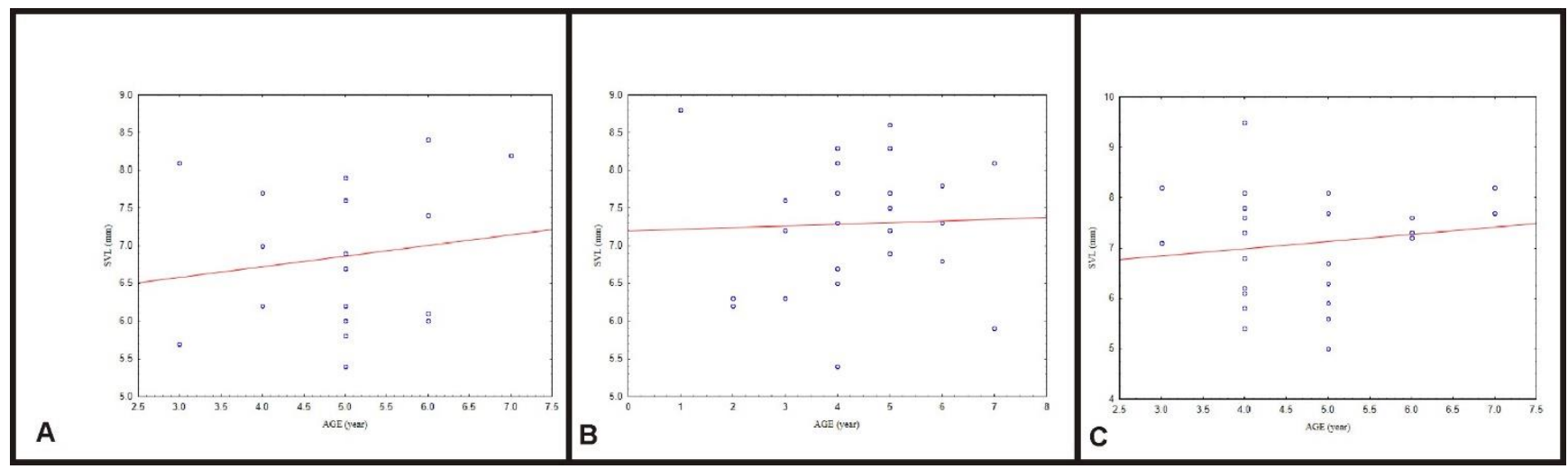

Figure 3. Growth curves between SVL and age in Heremites vittatus from three groups. A. group I, B. group II and C. group III

In the current study, the body size and age struture of $H$. vittatus from different populations in three elevations are compared. There are limited studies about age determination in the family Scincidae. Rohr (1997) stated that the mean age is $4.24 \pm 0.54$ in female individuals of Eulamprus tympanum from low altitude and is $7.16 \pm 0.67$ from high altitude. Dubey et al. (2013) indicated that the maximum age is 6 years in E. leuraensis. Smith et al. (2013) stated that the maximum age is 4 years in Ctenotus atlas. Kalayc1 et al. (2018) investigated that the age structure of $H$. vittatus in Sivas (Turkey) population. However, it is carried out with only one population (Sivas) and female individuals. Mermer et al. (2020) indicated that the mean age was calculated as 6 years (3-10 years) for males and 5.8 years (3-10 years) for females. The maximum life span was found to be 5 years for females of $H$. vittatus. Moreover, there is a significant relation between SVL and the age of $H$. vittatus. In the present study, we also investigated Sivas population, which includes in group III. In group III, the minimum age for female individuals is 3 years whereas the maximum one is 7 years. According to our result, there was no correlation between age and SVL for females and males (group III).

Sexual differences are used for morphological characters in ectothermic animals (Endler, 1992; Blanckenhorn, 2000; Yamahira and Conover, 2002). Intersexual differences in body size are caused by the ecological, behavioral and reproduction differences between males and females. In some species available in the literature, the mean SVL in females is bigger than males (Guarino et al., 2010, Lacerta 
agilis; Žagar et al., 2012, Iberolacerta horvathi, Podarcis muralis; Kanat and Tok, 2015, Hemidactylus turcicus; Yakın and Tok, 2015, Anatololacerta anatolica). Results of the previous studies showed that the body size variation in $H$. vittatus is available between sexes. Olsson and Shine (1997) stated that females with larger body size provide to increase clutch size and mass. The body size of females is correlated with fecundity whereas body size in males is related to mating success. Mating success is related to body size and behavioral features (Olsson and Madsen, 1998). In lacertids, many studies are related to male-biased in the warmer condition in terms of body size (Roitberg 2007; Gül et. al., 2014). According to our results, female-biased SSD was found in groups I and III. Females were larger than males, although male-biased SSD was found in $H$. vittatus. The highest SVL was found in group I (lowest site) for females while it was recorded in group II (middle site) for males. The finding of SVL changes in the literature (Gül et al., 2015a; Gül et al., 2015b; Bülbül et al., 2016a). In general, animals inhabited at low altitudes live shorter than those in higher elevation site. Roitberg and Smirina (2006) stated that the shorter activity period in the cooler area decreases the number of predators. The average age increases as the elevation increases (mean age in group I: 4.52; in group II: 4.71 and in group III: 4.84). The mean age is higher in group III ( 5 years in females and 4.61 years in males). The reason to be high mean age is caused by having the short active period of lizards in a highland population (group III). However, no significant difference in age among the three different altitudes. The underlying reason is that we did not study three populations from three different altitudes. We made a collection from different twenty-four populations.

Medium-sized species examined here is found in a wide variety of habitats. This species inhabits from sea level up to $2500 \mathrm{~m}$ asl. Specimens of $H$. vittatus examined here were investigated at three groups along the altitudinal gradients from 9 to $2042 \mathrm{~m}$. High altitude sites address the low temperature and food ability, and short activity period (Nagy and Grabherr, 2009). In general, specimens from highelevation sites and northern latitudes live longer than those from low-elevations sites and southern latitudes (Roitberg and Smirina, 2006b). Environmental factors are likely to reflect intraspecific body size variation of specimens along altitudinal gradients. This variation is related to the active season length (Sears, 2005). Because of the shorter activity seasons, specimens need more years to reach adult form (Karl and Fisher, 2009).

Many factors such as elevation, drought, climate, interspecific competition and predator-prey interactions make differences in age structure and other life-history traits of lizards (Roitberg and Smirina 2006a; Roitberg and Smirina 2006b; Gül et al., 2014). Özdemir et al. (2012) indicated that different environmental factors might affect population age structure. Roitberg and Smirina (2006b) reported that there is an increase in the mean age of lizard species from the colder condition. Moreover, the low mean age may also be seen in low altitude populations: 2.21 years were found in an island population of Podarcis siculus (Raia et al. 2010) and 4.12 years in Eremias argus (Kim et al. 2010). Age structure, body size and longevity of reptiles are different among the population of the same species. For example, the age of Lacerta agilis from the small village of Ferrere (Italy) was 4 years in males and 3 years in females while the age of individuals of the same species from the wetern coast of Sweden is 11 years for males and 12 years for females (Olsson and Shine, 1996; Guarino et al., 2010).

\section{CONCLUSION}

Herein, we compared body size, age structure and longevity of twenty-four populations of $H$. vittatus from different altitudes. The current study shows that the mean age of populations increases with high altitudes whereas the mean SVL of populations decreases. Moreover, females are larger than 
males, although male-biased SSD occurs in twenty-four populations of $H$. vittatus. Thus, it may be related to less competition and high food availability in high altitudes.

\section{ACKNOWLEDGEMENTS}

This work was supported by Dokuz Eylul University Scientific Research Coordination Unit. Project Number: 2017.KB.FEN.023

\section{Conflict of Interest}

The article authors declare that there is no conflict of interest between them.

\section{Author's Contilbutions}

The authors declare that they have contributed equally to the article.

\section{REFERENCES}

Altunışık A, Gül Ç, Özdemir N, Tosunoğlu M, Ergül T, 2013. Age structure and body size of the Strauch's racerunner, Eremias strauchi strauchi Kessler, 1878. Turkish Journal of Zoology, $37: 539-543$.

Altunışık A, Kalaycı TE, Uysal İ, Tosunoğlu M, Özdemir N, 2016. Age, adult survival rate and adult life expectancy of a Podarcis tauricus population (Reptilia: Lacertidae) from Saros Bay, Turkey. Russian Journal of Herpetology, 23(4):278-282.

Altunış1k A, Eksilmez H, 2018. Demographic life-history traits in a population of a critically endangered species, Darevskia dryada (Darevsky \& Tuniyev, 1997). Animal Biology, 0:1-11.

Arakelyan M, Petrosayan R, Ilgaz Ç, Kumlutas Y, Durmus SH, Tayhan Y, Danielyan F, 2013. A skeletochronological study of parthenogenetic lizards of genus Darevskia from Turkey. Acta Herpetoogica, 8(2):99- 104.

Baran İ, Ilgaz Ç, Avcı A, Kumlutaş Y, Olgun K (2012) Türkiye am- fibi ve sürüngenleri. TÜBİTAK Popüler Bilim Kitapları, Ankara. [In Turkish]

Bauer AM, 2003. On the identity of Lacerta punctata Linnaeus 1758, the type species of the genus Euprepis Wagler 1830, and the generic assignment of Afro- Malagasy skinks. African Journal of Herpetology, 52:1-7.

Blanckenhorn WU, 2000. Temperature effects on egg size and their fitness consequences in the yellow dung fly Scathophaga stercoraria. Evolutionary Ecology, 14:627-643

Bülbül U, Kurnaz M, Eroglu AI, Koç H, Kutrup B, 2016a. Age and growth of the red-belied lizard, Darevskia parvula. Animal Biology, 66:81-95.

Bülbül U, Kurnaz M, Eroğlu Aİ, Koç H, Kutrup B, 2016b. Body size anda ge structure of the endangered Clark's lizard (Darevskia clarkorum) populations from two different altitudes in Turkey. Amphibia-Reptilia, 37(4):450-456.

Cabezas-Cartes F, Boretto JM, Ibargüengoytía NR, 2015. Age, growth and life-history parameters of an endemic vulnerable lizard from Patagonia, Argentina. Journal of Herpetology, 25: 215-224.

Dubey S, Sinsch U, Dehling MJ, Chevalley M, Shine R, 2013. Population demography of an endangered lizard, the Blue Mountains Water Skink, BMC Ecology, 13(1):4.

Endler JA, 1992. Geographic variation, speciation, and clines. Princeton University Press, Princeton.

Eroğlu AI, Bülbül U, Kurnaz M, 2017. Age structure and growth in a Turkish population of the Italian wall lizard Podarcis siculus (Rafinesque-Schmaltz, 1810) (Reptilia: Lacertidae). Acta Zoologica Bulgarica, 69:209-214. 
Eroğlu Aİ, Bülbül U, Kurnaz M, Odabaşı Y, 2018. Age and growth of the common Wall lizard, Podarcis muralis (Laurenti, 1768), Animal Biology, 0:1-13.

Grimm A, Ramirez AMP, Moulherat S, Reynaud J, Henle K, 2014. Life-history trait database of European reptile species. Nature Conservation, 9:45 - 67.

Guarino FM, Gia ID, Sindaco R, 2010. Age and growth of the sand lizards (Lacerta agilis) from a high Alpine population of north-western Italy. Acta Herpetol, 5:23-29.

Güçlü S, Candan K, Lankiliç T, Kumlutaş Y, Durmuş SH, Poulakakis N, Ilgaz Ç, 2014. Phylogeny of Trachylepis sp. (Reptilia) from Turkey infferred from mtDNA sequences. Mitochondria DNA, 25(6):456-463.

Gül S, Özdemir N, Kumlutaş Y, Ilgaz Ç, 2014. Age structure and body size in three populations of Darevskia rudis (Bedriaga, 1886) from different altitudes. Herpetozoa, 26:151 - 158.

Gül S, Özdemir N, Avcı A, Kumlutaş Y, Ilgaz Ç, 2015a. Altitudinal effects on the life history of the Anatolian lizard (Apathya cappadocica, Werner 1902) from southeastern Anatolia, Turkey. Turkish Journal of Zoology, 39:507 - 512.

Gül S, Özdemir N, Kumlutas Y, Durmus SH, Ilgaz Ç, 2015b. Age structure and body size variation in populations of Darevskia bithynica (Méhely, 1909) (Reptilia: Lacertidae) from different altitudes in Northwestern Turkey. Acta Zoologica Bulgarica, 67(4):487-491.

James CD, 1991. Growth rates and ages at maturity of sympatric scincid lizards (Ctenotus) in central Australia. Journal of Herpetology, 25:284-295.

Kalaycı TE, Altunışık A, Uysal İ, Tosunoğlu M, Özdemir N, 2018. Age determination of Heremites vittatus (Bridled Skink) (Oliver, 1804) using skeletochronology in Sivas population, Turkey. Biological Diversity and Conservation, 11(2):1-6.

Kanat B, Tok V, 2015. Age structure of Hemidatctylus turcicus (L., 1758) (Sauria: Gekkonidae) from southwestern Anatolis (Muğla, Turkey). Turkish Journal of Zoology, 39:373-377.

Karin BR, Metallinou M, Weinell JL, Jackman TR, Bauer AM, 2016. Resolving the higher-order phylogenetic relationships of the circumtropical Mabuya group (Squamata: Scincidae): an out-ofAsia diversification. Molecular Phylogenetics and Evolution, 102:220-232.

Karl I, Fischer K, 2009. Altitudinal and environmental variation in lifespan in Copper butterly Lycaena tityrus. Functional Ecology, 23:1132-1138

Kim JK, Song JY, Lee JH, Park D, 2010. Physical characteristics and age structure of Mongolian racerunner (Eremias argus; Larcertidae; Reptilia). Journal of Ecology Field Biology, 33: 325-331.

Kolarov TN, Vljevic LK, Polovic LDG, Kalezic ML, 2010. The body size, age structure and growth pattern of the endemic Balkan mosor rock lizard (Dinolacerta mosorensis kolombatovich, 1886). Acta Zoologica Academiae Scientiarum Hunggaricae, 56:55-71.

Kumlutaş Y, Candan K, Ilgaz Ç, 2015. A new locality record of Trachylepis vittata (Oliver, 1804) (Reptilia: Scincidae) in Nortyheastern Anatolia, Turkey. Russian Journal of Herpetology, 22(4):310-314.

Kurnaz M, Eroğlu Aİ, Bülbül U, Koç H, Kutrup B, 2017. The life-history traits in a breeding population of Darevskia valentini from Turkey. Acta Herpetologica, 12(2): 167-173.

Lovich E, Gibbons JW, 1992. A review of techniques for quantifying sexual size dimorphism. Growth Dev Aging, 56:269-281.

Mausfeld P, Vences M, Schmitz A, Veith M, 2000. First data on the molecular phylogeography of scincid lizards of the genus Mabuya. Molecular Phylogenetic Evolution, 17:11-14. 
Mausfeld P, Schmitz A, Böhme W, Misof B, Vrcibradic D, Rocha CFD, 2002. Phylogenetic affinities of Mabuya atlantica Schmidt, 1945, endemic to the Atlantic ocean archipelago of Fernando de Noronha (Brazil): necessity of partitioning the genus Mabuya Fitzinger, 1826 (Scincidae: Lygosominae). Zool. Anz. 241:281-293.

Nagy L, Grabherr H, 2009. The Biology of Alpine Habitats. Oxford: Oxford University Press.

Mermer A, Kumaş M, Mutlu HS, Çiçek K, 2020. Age structure of a population of Chalcides ocellatus (Forskal, 1775) (Sauria: Scincidae) in Mediterranean Anatolia. Zoology in the Middle East, http://dx.doi.org/10.1080/09397140.2020.1781362.

Orlova VF, Smirina EM, 1983. Age determination of Lacerta derjugini Nik. in natural populations. Biologicheskie Nauki, 9:53-57.

Olsson M, Shine R, 1996. Does reproductive success increase with age or with size in species with indeterminate growth? A case study using sand lizards (Lacerta agilis). Oecologia, 05:175-178.

Olsson M, Madsen T, 1998. Sexual selection and sperm competition in reptiles. In: Sperm Competition and Sexual Selection (T. R. Birkhead \& A. P. Møller, eds), pp. 503-578. Academic Press, London.

Özdemir N, Altunışık A, Ergül T, Gül S, Tosunoğlu M, Cadeddu G, Giacoma C, 2012. Variation in body size and age structure among three Turkish populations of the treefrog Hyla arborea. AmphibiaReptilia, 33:25-35.

Raia P, Guarino FM, Turano M, Polese G, Rippa D, Carotenuto F, Monti DM, Cardi M, Fulgione D, 2010. The blue lizard spandrel and the island syndrome. BMC Evolutionary Biology, 10:289.

Rastegar-Pouyani, N., Fattahi, R., \& Gholamifard, A. (2013). Cranial osteology of the Bridled Shink, Trachylepis vittata (Oliver, 1804) and its comparison with Trachylepis aurata transcaucasica (Chernov, 1926) (Sauria: Scincidae). Russian Journal of Herpetology. 20(4): 276-286.

Rastegar-Pouyani, N, Fattahi R, 2015. Sexual dimorphism in Trachylepis vittata (Olivier, 1804) (Sauria: Scincidae) in the Zagros Mountains, western Iran. Turkish Journal of Zoology, 39:59-65

Rohr DH, 1997. Demographic and life-history variation in two proximate populations of a viviparous skink separated by a steep altitudinal gradient. Journal of Animal Ecology, 66:567-578.

Roitberg ES, Smirina EM, 2006a. Adult body length and sexual size dimorphism in Lacerta agilis boemica (Reptilia, Lacertidae): between-year and interlocality variation. In: Corti C, Lo Cascio P, Biaggini M, editors. Mainland and Insular Lacertid Lizards: A Mediterranean Perspective. Florence, Italy: Firenze University Press, pp. 175-187.

Roitberg ES, Smirina EM, 2006b. Age, body size, and growth of Lacerta agilis boemica and L. agilis strigata: a comparative study of two closely related lizard species based on skeletochronology. Journal of Herpetology, 16:133-148.

Roitberg ES, 2007. Variation in sexual size dimorphism within a widespread lizard species, Pp. 143 217. In: Farrbairn, D.J., Black enhorn, W.U. \& Szekely, T. (Eds.): Sex, Size, and Gender Roles: Evolutionary Studies of Sexual Size Dimorphism. Oxford Unıversity Press, New York, USA, 280 pp.

Sears MW, 2005. Geographic variation in the life history of the sagebrush lizard: the role of thermal constraints on activity. Oecologia, 143:25-36.

Tomaševiæ K, Ljubisavljeviæ K, Poloviæ L, Dukiæ G, Kaleziæ ML, 2010. The body size, age structure and growth pattern of the endemic Balkan mosor rock lizard (Dinarolacerta mosorensis Kolombatoviæ, 1886). Acta Zoologica Academiae Scientiarum Hunggaricae, 56:55 - 71. 
Üzüm N, Avcı A, Kumlutas Y, Beser N, Ilgaz Ç, 2015. The first record of age structure and body size of the Suphan Racerunner, Eremias suphani Basoglu \& Hellmich, 1968. Turkish Journal of Zoolgy, 39:513-518.

Üzüm N, Ilgaz Ç, Avcı A, Candan K, Güler H, Kumlutaş Y, 2018. Comparison of the body size anda ge structure of Lebanon Lizard, Phoenicolacerta laevis (Gray, 1838) at different altitudes in Turkey. Vertebrate Zoology, 68(1):83-90.

Wapstra E, Swan R, O’Reilly JM, 2001. Geographic variation in age and size at maturity in a small Australian viviparous skink. Copeia, 2001:646-655.

Whiting AS, Sites JW, Pellegrino KCM, Rodrigues MT, 2006. Comparing alignment methods for inferring the history of the new world lizard genus Mabuya (Squamata: Scincidae). Molecular Phylogenetics and Evolution, 38:719-730.

Yakın BY, Tok CV, 2015. Age estimation of Anatololacerta anatolica (Werner, 1902) in the vicinity of Çanakkale, by skeletochronology. Turkish Journal of Zoology, 39:66 - 73.

Yamahira K, Conover DO, 2002. Intra- vs. interspecific latitudinal variation in growth: adaptation to temperature or seasonality? Ecology, 83:1252-1262

Žagar A, Osojnik N, Carretero MA, Vrezek A, 2012. Quantifying the intersexual and interspecific morphometric variation in two resembling sympatric lacertids: Iberolacerta horvathi and Podarcis muralis. Acta Herpetologica, 7:29 - 39. 